with doctors on a fee for service system as compared with those with salaried doctors. Thus not the monetary aspect as such, but rather something in the way the two different groups of doctors arrange or run their practices, seems to influence patient satisfaction. As has been found by other studies, ${ }^{14}$ the doctor's availability, here measured as the average hours of clinical practice a week, increased patient satisfaction with consultations. Inasmuch as patient satisfaction is important, part time partnerships and the ownership structure may be relevant factors to consider when planning primary health care systems.

Patients with psychosocial reasons for encounter showed significantly less satisfaction with their consultations than patients coming for other, usually somatic reasons. This may be due to the possibility that patients with psychosocial problems actually get inferior care. Psychosocial problems may be more time consuming, complex, and difficult for the physician to handle than somatic problems, or the patients may have unrealistic expectations of help. Another reason may be that these patients often are depressed or have unfavourable life circumstances. Studies suggest, however, that patients' assessments of service are relatively independent of depression and general life outlook, ${ }^{14}$ making this explanation less likely. This finding may furthermore be influenced by the new international classification of primary care system itself, recording the patient's major reason for consultation rather than the final diagnosis. When evaluating patient satisfaction, however, the reason for contact seems to be the most valid measure. With the patient-doctor relationship and continuity of care being integral parts of both diagnosis and treatment in patients with psychosocial problems, ${ }^{22}$ it seems important to further evaluate why these patients are less satisfied with their consultations.

The present study shows a link between personal, continuous care and patient satisfaction. If patient satisfaction is accepted as an integral part of quality health care, reinforcing personal care may be one way of increasing this quality.

1 Fitzpatrick R. Surveys of patient satisfaction. I. Important general considera tions. BMF 1991;302:887-9.

2 Roter D, Hall J, Katz N. Relations between physicians' behaviors and analogue patients' satisfaction, recall, and impressions. Med Care 1987;25: 437-51.

3 Fitzpatrick R, Hopkin A, Harvard-Watts O. Social dimensions of healing: a longitudinal study of outcomes of medical management of headaches. Soc Sci Med 1983;17:501-10.

4 Ware J, Snyder M. Dimensions of patient attitudes regarding doctors and medical services. Med Care 1975;13:669-79.

5 Freeman GK. Continuity of care in general practice: a review and a critique. Fam Pract 1984;1:245-52.

6 Banahan BF, Banahan BF III. Continuity as an attitudinal contract. 7 Fam Pract 1981;12:767-8.

7 Pendleton D, Schofield T, Tate P, Havelock P. The consultation: an approach to learning and teaching. Oxford: Oxford University Press, 1984

8 Hall JA, Dornan MC. What patients like about their medical care and how often they are asked: a meta-analysis of the satisfaction literature. Soc $S c i$ Med 1988;27:935-9.

9 Keeley D. Personal care or the polyclinic? BMf 1991;302:1514-6.

10 Hjortdahl P, Borchgrevink CF. Continuity of care: influence of general practitioners' knowledge about their patients on use of resources in consultations. BMF 1991;303:1181-4.

11 Lamberts $\mathrm{H}$, Wood $\mathrm{M}$, eds. ICPC: international classification of primary care. Oxford: Oxford University Press, 1987.

12 Hosmer DW, Lemeshow S. Applied logistic regression. New York: Wiley, 1989. 13 Rutle O. Pasienten fram i lyset-analyse av legekontaktar $i$ primerhelsetenesta [Getting the patient into the limelight: an analysis of encounters in primary [Getting the patient into the limelight: an analysis of encounters in primary
health care]. Oslo: Statens Institutt for Folkehelse, 1983. (Report

14 Pascoe GC. Patient satisfaction in primary health care: a literature review and analysis. Evaluation and Program Planning 1983;6:185-210.

15 Harris R. Improving patient satisfaction through action research. 7 Appl Behav Sci 1978;14:382-99.

16 Fitzpatrick R. Surveys of patient satisfaction. II. Designing a questionnaire and conducting a survey. BMF 1991;302:1129-32.

17 Hall JA, Dornan MC. Meta-analysis of satisfaction with medical care: description of research domain and analysis of overall satisfaction levels. Soc Sci Med 1988;27:637-44.

$18 \mathrm{McWhinney} \mathrm{IR.} \mathrm{A} \mathrm{textbook} \mathrm{of} \mathrm{family} \mathrm{medicine.} \mathrm{New} \mathrm{York:} \mathrm{Oxford} \mathrm{University}$ Press, 1989

19 Marquise MS, Davies AR, Ware JE. Patient satisfaction and change in medica care provider: a longitudinal study. Med Care 1983;21:821-9.

20 Hirschman AO. Exit, voice and loyalty: responses to decline in firms, organizations, and states. Cambridge, Massachusetts: Harvard University Press, 1970.

21 Hiortdahl P. General practice and continuity of care: organizational aspects. Fam Prac 1989;6:292-8.

22 Murphy M. Somatisation: embodying the problem. BMF 1989;298:1331-2.
University of Wales College of Medicine, Cardiff CF4 4XN Norman J Vetter, senior lecturer, department of epidemiology and community medicine

Peter A Lewis, senior lecturer, department of medical computing

Lise Llewellyn, lecturer, department of public health medicine

BMF 1992;304: 1290-2

\title{
Supporting elderly dependent people at home
}

\author{
Norman J Vetter, Peter A Lewis, Lise Llewellyn
}

Abstract

Objective-To clarify the relation between the dependency of elderly people and the assistance they receive from others by using a detailed but simple measure of dependency.

Design - Secondary analysis of data from a survey of people aged 70 and over.

Setting-Two general practices in south Wales.

Subjects -1280 people aged 70 and over.

Main outcome measures-Dependency on others to perform essential functions; detailed data on who assists with those functions.

Results-Increasing dependency was associated with increased use of more than one member of the family or friends and an increase in the provision of statutory services.

Conclusion-The complexity of the relation between dependency and those who care for dependent people has previously been underestimated. The presence of providers of statutory services at the household of elderly dependent people suggests that these services can be developed further to help those caring for elderly people at home.

\section{Introduction}

For many years it has been the policy of the Department of Health to maintain elderly people at home for as long as this remains a viable alternative. Most elderly people, when asked, agree with this and reinforce it by saying that, even if quite severely dependent on others, they would prefer to be managed at home. Further, they state that members of their family will be available to assist.

There are two aspects to the home care of elderly dependent people by their families: the degree of dependency of that person and the ability of the carer to cope in physical, mental, and social terms. Previous work has concentrated on the second aspect. This paper uses data from a previously published study ${ }^{2}$ to explore the interrelation between the dependency of elderly people and the contribution made to their care by relatives, friends, and the statutory services. This reanalysis has led us to revise the original findings of the survey.

We believe that survey groups and methods used previously on this topic have inadvertently led to an underemphasis on the contribution that service providers make to the home care of elderly dependent people. This has had important repercussions on the development of relevant services.

\section{Method}

This paper presents a reanalysis of data obtained from a study published previously, which was the first 
to examine the needs of family members and service providers in the general population, rather than being based on groups of elderly people in touch with different services. ${ }^{2}$

Two general practices in south Wales that represented typical urban and rural settings were chosen. The first, in Gwent, consisted of a highly populated inner city area with neighbouring council and private housing estates. The study group contained a randomly chosen $40 \%$ of those on the practice list aged 70 and over found to be alive and still in the area ( 683 people). The second, in Powys, covered an area of about 400 square miles with small towns and large numbers of isolated outlying farms. The study group included all of the over 70 s on the practice list still alive and in the area (659 people).

The interviewers had had previous experience of interviewing in market research or government sponsored social surveys, or both. The need of an elderly person for assistance was defined by a description of a selection of daily activities that he or she was unable to perform. This has been described in a

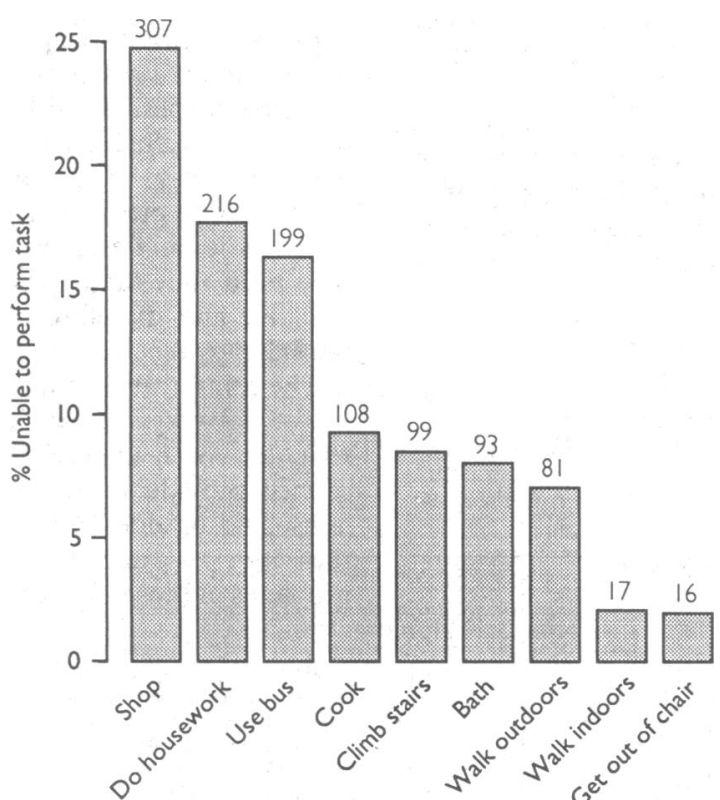

FIG 1-Proportion of people aged over 70 unable to perform certain tasks
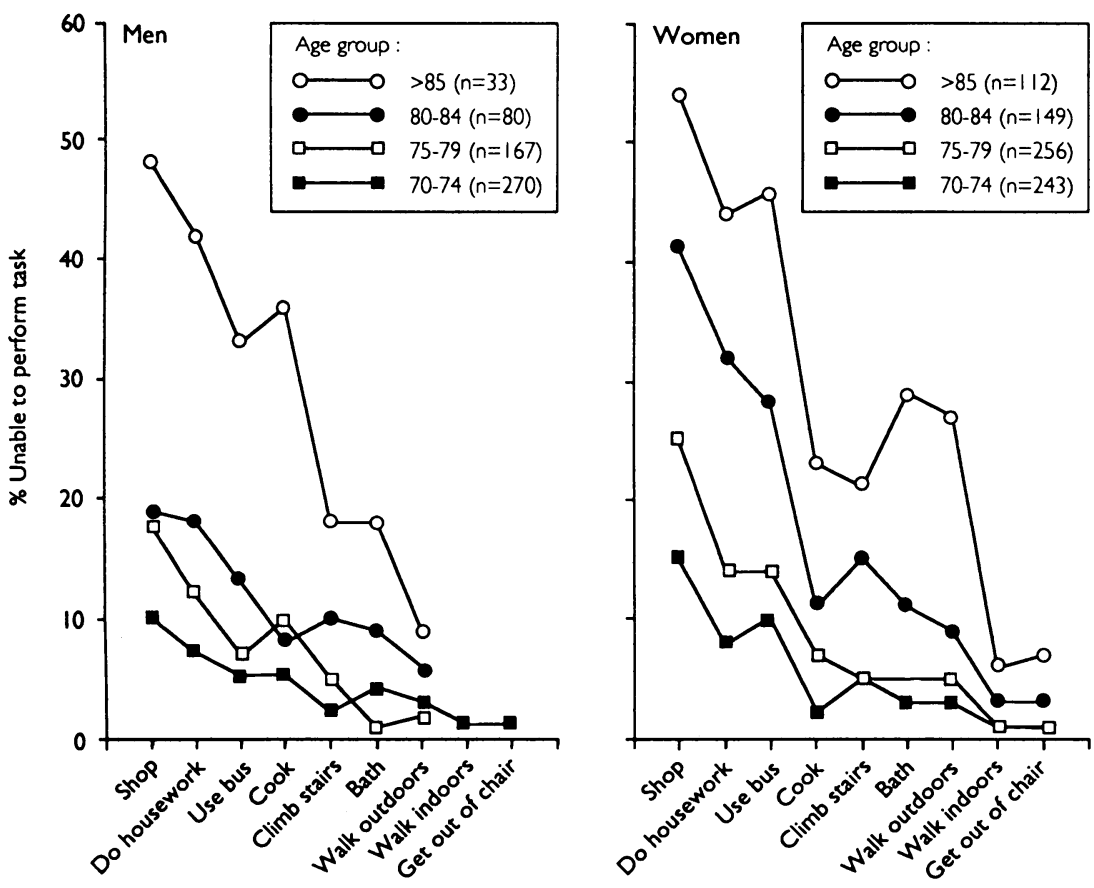

FIG 2-Proportion of men (left) and women (right) aged over 70 unable to perform certain tasks previous study that outlined the relation between dependency and symptoms in 2700 people aged 60 and over. ${ }^{3}$ Those activities that a high proportion of the population was unable to perform were perceived to be less severe than those that a low proportion was unable to execute.

This reanalysis used a direct approach to the classification of dependency to simplify the description of the needs of elderly people and the pressure such needs put on different family members and service providers. The tasks for which the elderly person was dependent on others were not presented as a definitive or exhaustive list. The model may be used for any tasks that are important in a particular context.

When data about the dependency of the elderly person (that is, those activities which the elderly person was unable to perform) had been obtained that person was questioned about who assisted with those functions. Details were noted of up to five different family members, friends, neighbours, and statutory and other services involved.

\section{Results}

Of the 1342 people in the study group, 1280 (95\%) responded to all of the questions used in this paper. All of the non-respondents were refusals; no cases were lost. Figure 1 shows the proportion and number of people in the study who were dependent on others for a range of tasks from shopping to getting out of a chair, standard items used to describe dependency. The figures for the proportion of the population unable to perform each task alone were placed in rank order for the whole population. The items thus form a gradation of severity.

This progression also fits with the most commonly used classification of dependency, the interval method. ${ }^{4}$ Those with critical interval dependency, who need care at any time at irregular intervals, would be those unable to get out of a chair or walk indoors; those with short interval dependency, requiring assistance at least once a day, would be unable to cook, go outside, bath, or climb stairs. Those with long interval dependency are unable to perform actions that need to be undertaken at least once a week: doing housework and shopping.

Figure 2 shows the dependency data by age and sex of the subjects. There is a clear gradation with age; older people are more dependent than younger in all of these functions. The figures show the extent of this with different age groups and emphasise the high prevalence of dependency in the oldest age groups.

The proportion of women who are dependent is greater than that of men in virtually all of the groups shown. There is a little difference in the ranking of the tasks between men and women, except that at all ages relatively few women are unable to cook. The proportions of men who are severely dependent are very low. In terms of service needs (that is, the number of people in a population who require assistance) this sex difference is even more extreme as women predominate numerically, especially in the older age groups, due to their longer life expectancy.

Table I shows the proportion of people who were dependent and who were assisted by family members or service providers. A single unpaid person, who was usually a relative, formed the majority of those who cared for this group of dependent people. These individuals were most often daughters or the elderly person's spouse. For about a fifth of the dependent elderly people more than one unpaid person shared with helping. A further fifth of elderly people were assisted by one unpaid person with the help of a statutory service. For about a tenth, more than one member of the family or a friend shared with a service 
provider and services alone provided assistance for a further tenth.

Figure 3 shows whether assistance to the dependent men and women was provided by one or more relatives, services, or a combination of relatives and services. There are important differences between those with mild or severe forms of dependency. No person was cared for by services alone in the most severe categories, but the proportion of people cared for by another single person, who was virtually always a relative, decreased as dependency increased. The proportion of elderly people cared for by several relatives together and relatives in combination with services increased with increasing dependence. There was thus a trend for more people to become involved as dependency increased.

\section{Discussion}

This analysis shows the complexity of the relation between dependent elderly people living at home and their carers. It supports the existing view that one person, usually a daughter or spouse, makes a major contribution to caring. It also shows that the statutory services were often involved with caring for highly dependent elderly people.

Many previous studies, including our own initial analysis, have concentrated on the pressure on carers, paying relatively little attention to the severity of the dependency of the elderly person. There has also been a tendency to oversimplify the carer's role by concen-

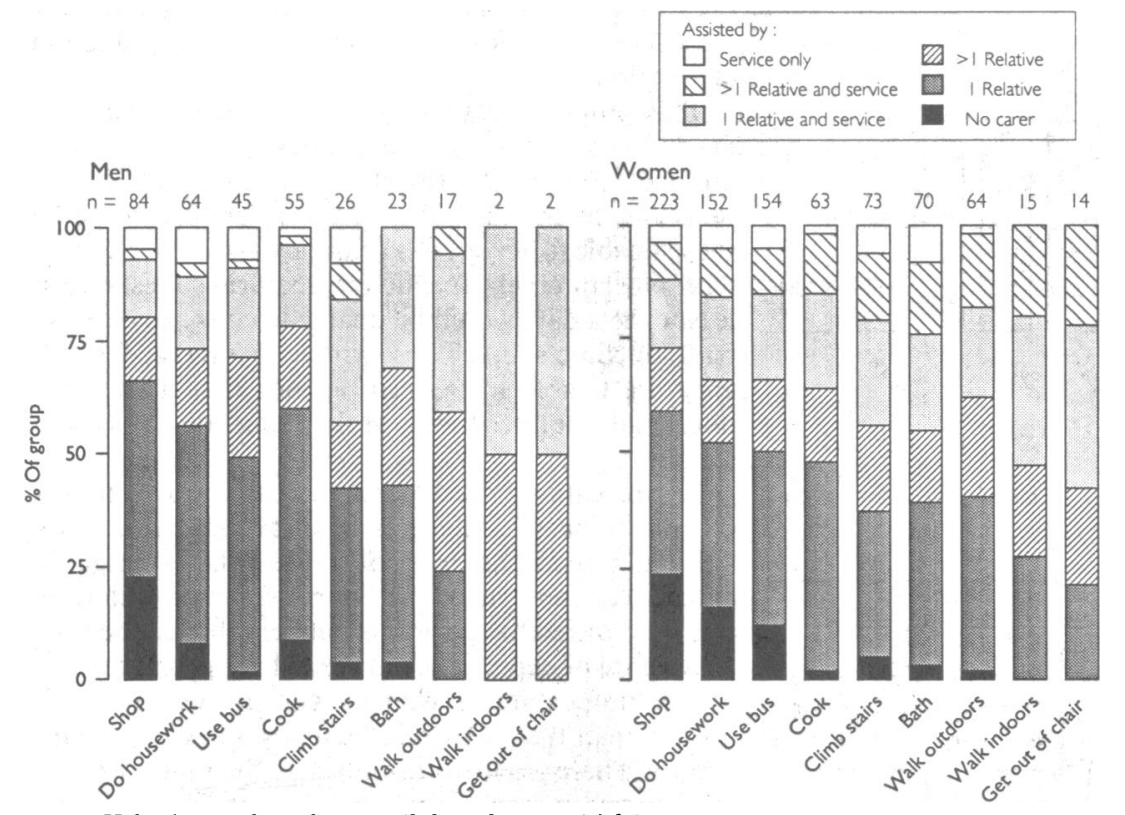

FIG 3-Help given to dependent men (left) and women (right)
Help given to dependent people aged over 70

\begin{tabular}{lcc}
\hline Source of help & No (\%) requiring help \\
\hline 1 Relative & 74 & 179 \\
Daughter & 54 & \\
Spouse & 5 & \\
Son & 12 & \\
Sibling & 13 & \\
Other relative & 9 & \\
Friend & 12 & 58 \\
Other & & 56 \\
1 Relative & & 22 \\
1 Relative and service & & 22 \\
1 Relative and service & & \\
Service only & & \\
\hline
\end{tabular}

trating on the main carer. This tendency continues in more recent studies on those caring for elderly people.

In some studies data have been obtained from people already in contact with services, including those newly discharged from hospital, people in day centres, and carers' groups. ${ }^{56}$ Such groups of people will be biased towards families who are well informed about the services needed.

Other surveys on the needs of those who care for dependent elderly people have highlighted the costs to the family of performing such tasks and the degree of stress experienced by family members. ${ }^{7-9}$ This approach is valuable from the carer's perspective but does not always lead to an obvious conclusion about where service provision is already available and therefore how it can develop. When carers are asked what they need they often lack information about what is available and therefore suggest more of the services they already receive.

The complexity of the relation between dependency and those who care for dependent people has, in the past, led to an underestimate of the contribution of service providers. The presence of services at the household of elderly dependent people suggests that these services can be further developed to alleviate the problems of those caring for elderly people at home.

1 Salvage AV, Vetter NJ, Jones DA. Attitudes to hospital care among a community sample of people aged 75 and older. Age Ageing 1988;17:270-4

2 Vetter NJ, Jones DA, Victor CR. Effect of health visitors working with elderly patients in general practice: a randomised controlled trial. BMJ 1984;288: 369-72.

3 Vetter NJ, Lewis PA, Ford D. The relationship between symptoms of chronic disease and dependence. Intermational Disability Studies 1990;12:22-7.

Isaacs B. Geriatric patients: do their families care? BMf 1971 ;iv:282-6.

Koopman Boyden PG, Wells LF. The problems arising from supporting the elderly at home. $N Z$ Med $\mathcal{F}$ 1979;89:265-8.

6 Nissel $M$. The family costs of looking after handicapped elderly relatives Ageing and Society 1984;4:185-204.

Brody EM. Women in the middle: family help and older people. The Gerontologist 1981;21:471-81.

8 Jones DA, Vetter NJ. A survey of those who care for the elderly at home: their problems and their needs. Soc Sci Med 1984;19:511-4.

9 Equal Opportunities Commission. The experience of caring for elderly and handicapped dependents: survey report. Manchester: EOC, 1980.

(Accepted 6 March 1992)

\section{ONE HUNDRED YEARS AGO}

\section{A CHEAP MILITARY REFORM.}

The youth and health of our home army are an important study. It has been pointed out by Lieut.-Colonel Allsopp and others in our columns how it is possible at a minimum of cost to do much to improve the physique of the young lads who compose it. Free rations do not include tea and breakfast; these the soldier finds from his pay. All our readers are aware that no one in civil or military life commences an excursion with "a sinking stomach." Experience enables Lieut.-Col. Allsopp to state that few things promote sobriety and discipline, improve the health and physique of our young soldiers more than an early ration of cocoa and biscuits before the morning drill. The best cocoa must be used; it goes the farthest. We recommend cocoa; it is easily prepared, assimilates in the stomach without milk or sugar, and is very nutritious. This is a modest and a practical reform. We invite the War Minister to consider its adoption as an additional incentive to recruiting, a sure and certain method of ameliorating the physical welfare of the British soldier, and thereby promoting contentment in the ranks.

(BMF 1892;i:82) 